\title{
Gutiérrez Nájera y Martí como Iniciadores del Modernismo
}

$\mathrm{E}$ $\mathrm{N}$ su valioso libro Símbolo y color en la obra de José Marti,* el profesor Iván Schulman, además de su propósito principal de mostrar el nexo existente entre los símbolos martianos y sus motivaciones psicológicas, parece tener otro, aun cuando de orden secundario: el de demostrar la prioridad de Martí sobre Gutiérrez Nájera como iniciador del Modernismo. Querer aprovechar esta oportunidad para examinar las pruebas que se aducen en apoyo de su punto de vista, no quiere decir que nos anime el deseo de romper lanzas polémicas. Más bien el propósito que nos guía no es otro que el de llamar la atención del profesor Schulman sobre dos libros míos. ${ }^{1} \mathrm{El}$ mismo profesor Schulman reseñó el primero de ellos (véase Revista Hispánica Moderna, XXIII, núm. 2, abril de 1957 , pp. I63-I64), pero no pudo conocer el segundo al componer su libro, por razón de fechas.

En los libros aludidos se encuentran varios escritos inéditos de El Duque Job asi como datos biográficos y otra documentación de interés que han de tomarse en cuenta, según creemos, antes de poder conceder a Martí, en forma definitiva, los laureles de primer iniciador del Modernismo.

En su artículo sobre "Función y sentido del color en la poesía de Manuel Gutiérrez Nájera","2 el profesor Schulman nota que "La cuestión de prioridad, no sólo en materia cromática, sino en otras esferas de la estilística modernista, plantea toda una serie de problemas espinosos". 3

* Para la reseña que consagramos a este libro, véase Revista Iberoamericana, núm. 53 (enero-junio 1962), pp. 216-221.

1. Boyd G. Carter, Manuel Gutiérrez Nájera-Estudio y escritos inéditos. México, Colección Studium 12, Ediciones de Andrea, 1956.

- En torno a Gutiérrez Nájera y las letras mexicanas del siglo XIX. México, Ediciones Botas, 1960.

2 Véase Revista Hispánica Moderna, año XXIII (enero 1957), pp. 1-13.

3 Ibid, p. 2. 
Pero en este artículo, más bien que de la anticipación modernista de Martí sobre Gutiérrez Nájera, se ocupa de la prioridad de Martí y de Gutiérrez Nájera sobre Darío. "Es probable -opina el doctor Schulman- que el mismo Darío haya dado origen a este modo de enfocar la historia del Modernismo con su ególatra afirmación: 'El movimiento de libertad que me tocó iniciar en América..."'4 Fue en el Prólogo a Cantos de vida y esperanza (I905) donde Rubén juzgó en estos términos el alcance de su contribución al desarrollo del movimiento modernista. También en I905, en el prólogo a la segunda edición de Los Raros, asienta Rubén más o menos la misma opinión: "Me tocó dar a conocer en América ese movimiento y por ello y por mis versos de entonces, fui atacado y calificado con la inevitable palabra "decadente'..."

El doctor Schulman comparte la opinión de aquellos investigadores y críticos, por cierto cada vez más numerosos, que ya no admiten la fecha de I888, año de la aparición de $A z u l$, como la de la iniciación del Modernismo. Las pruebas que aduce el profesor Schulman, tanto en el artículo aludido (en la nota 2) como en otro titulado "Los supuestos 'precursores' del modernismo hispanoamericano", 5 contribuye a sostener la tesis de que Gutiérrez Nájera, Martí, Casal y Silva más bien que ser los "precursores" del Modernismo, como hasta en los recientes años la crítica en su mayor parte solía designarlos, son en realidad los "iniciadores" de dicho movimiento. Ciertamente en los escritos de Gutiérrez Nájera y de Martí aparecidos de 1876 a 1888 , se encuentran casi todos aquellos elementos y rasgos característicos que, tanto con respecto al estilo como al contenido, se identifican con el conjunto de tendencias y expresiones del movimiento en cuestión. En dicha producción literaria inicial también se pone de relieve la plena conciencia de la nueva orientación estética y crítica que ellos estaban dando a las letras hispanoamericanas. Decimos esto porque en la obra de ambos, aun cuando de menos significación histórica que la de escritores como Poe, Baudelaire y Mallarmé, la función crítica se encuentra hasta cierto grado en íntima alianza con la estructura y elaboración que quisieron dar a muchos de sus escritos.

El profesor Schulman sostiene que a Martí y a Gutiérrez Nájera debe concedérseles el título de iniciadores $-\mathrm{y}$ no el de precursores del Modernismo-, por cuanto en sus escritos anteriores a I 888 ya se encuentran elementos fundamentales del movimiento. No parece disentir en di-

4 Ibíd.

5 En la Nueva Revista de Filología Hispánica, vol. XII (enero-marzo 1958), pp. 61-64. 
chos artículos del juicio (que cita) de Max Henríquez Ureña de que Gutiérrez Nájera "... fue el primero que en las letras de América profesa especial devoción por los colores". ${ }^{6}$ Sin embargo, se nota en su libro, Simbolo y color en la obra de José Martí, que ya no se aviene con esta afirmación y parece querer arrebatarle a El Duque Job la prioridad de iniciador en el campo que le concede Henríquez Ureña, para conferírsela a José Martí. Además, el afán del profesor Schulman no se limita sólo al propósito de conseguir la "cronológica desvalorización cromática" de nuestro poeta. Al parecer, quisiera establecer también la prioridad de Martí como teórico del movimiento modernista.

Con respecto al uso literario del color en la obra de Martí, observa el profesor Schulman que: "De hecho, Martí se dio cuenta de las posibilidades literarias del color en fecha tan temprana como I875, es decir, dos años antes de recogerse el primer cuento de Manuel Gutiérrez Nájera y un año antes de que apareciera la primera composición cromática de importancia en la poesía de Nájera: "Luz y Sombra" (p. 458). En otro lugar dice el autor: "Ya en I875 usaba azul Martí simbólicamente con típicas connotaciones modernistas: ' . .. ama [Pedro Castera] lo azul, porque lo azul da idea poética del exquisito espíritu por quien siente amor tan alto...' Un año después, Manuel Gutiérrez Nájera, otro iniciador del modernismo, compuso el verso siguiente en 'Luz y Sombra', 'Es blanca tu conciencia y azul tu pensamiento" ". (p. 345, nota I27).

Afirmaciones de la misma índole, todas encaminadas al propósito de demostrar la prioridad de Martí sobre Gutiérrez Nájera en el uso de colores, se hallan en las páginas siguientes: 195, 228, 305-306, 438-439 (nota 39), 472, 522. Si bien, por ejemplo, en la página 455 , parece que le concede a MGN tal vez el rango de coiniciador, notamos que se lo quita en la nota 40 (p. 512). Asi en la página 455 leemos: "Muchos de los valores cromáticos que hallamos en su obra están patentes también en la de otros modernistas, si bien, por lo general, en fecha posterior (Nájera es una excepción notable)". Y en la nota 40 (p. 512), "Max Henríquez Ureña considera a Nájera el iniciador de los efectos coloristas en la prosa modernista (op cit., págs. 27 y 68), pero M. P. González, en su artículo 'Conciencia y voluntad de estilo en Matti' establece la anterioridad cronológica de Marti"."?

6 Breve bistoria del modernismo (véase Schulman, Revista Hispánica Moderna, op cit., p. 2).

7 Publicado en Libro jubilar de Emeterio S. Santovenia en su cincuentenario de escritor. La Habana, 1957, pp. 121-227. No hemos visto el artículo del pro- 


\section{II}

Veamos ahora las pruebas que aduce el profesor Schulman para afirmar que le corresponde a Martí la prioridad de ser el iniciador del Modernismo en cuanto al uso de colores. Se citan dos ejemplos del empleo de la palabra azul, ambos en prosa, y un comentario de alcance crítico sobre la función de los colores; los tres se remontan al año I875. Nos limitamos a comentar estos tres ejemplos, si bien puede haber otro que no hayamos podido notar.

Las citas aludidas son: ". . ama [Pedro Castera] lo azul, porque lo azul da idea poética del exquisito espíritu por quien siente amor tan alto..." (p. 345). "Más puede la simpatía que la envidia, porque hay sobre la tierra más flores que serpientes, y en el cielo más nubes azules que oscuridades anunciadoras de huracán" (p. 228). "El color tiene más cambiantes que la palabra, así como en la gradación de las expresiones de la belleza, el sonido tiene más variantes que el color..." (p. 458). Es cierto que en estas citas se encierran pruebas de la conciencia que a la sazón tenía Martí de la función potencial que podrian desempeñar los colores como medios de la expresión simbólica. De esto no nos cabe la menor duda. De lo que sí queremos disentir es de la afirmación de que el uso que Martí hace del color azul en dichos ejemplos, en 1875 , deba ser equiparado en cuanto a su importancia con el que de este mismo color hace MGN, en $x 876$, en una composición del logro estético de "Luz y Sombra". El verso, "Es blanca tu conciencia y azul til pensamiento", que aparece en este poema, forma parte de una poesía de reconocido valor poético. ¿Se puede decir lo mismo de los ejemplos de Martí citados por el profesor Schulman? Además, Gutiérrez Nájera también usó el color azul en la estrofa siguiente del poema "Serenata", dado a la luz pública en octubre de 1875 .

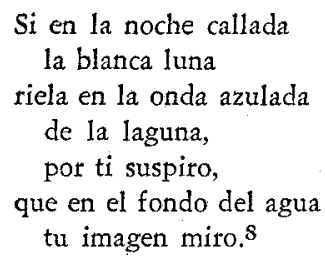

fesor González; por tanto no sabemos si conocía nuestro libro Manuel Gutiérrez Nájera - Estudio y escritos inéditos, aparecido en 1956.

8 Poesías completas, Edición y prólogo de Francisco González Guerrero, Editorial Porrúa, México, 1953, T. I., p. 82. 
No hay que esforzar la imaginación para ver en esta estrofa la simbólica unidad de "tu imagen" (por la que suspira el poeta) con el color del agua en el fondo de la laguna.

Además, la imagen que se refleja no podría menos de ser una imagen de color azul, considerando que se la mira en la onda azulada.

En I960 reprodujimos un poema titulado "Una flor"9 firmado "M. Gutiérrez" que apareció en la revista El Búcaro en el verano de 1874 . Según la evidencia que se puede aducir, es "M. Gutiérrez" en este caso Manuel Gutiérrez Nájera y no su padre, quien se sirvió también de esta firma. Si no nos equivocamos, es el primer escrito publicado de MGN del que tenemos conocimiento. En este poema, queremos señalar la estrofa siguiente:

\section{Virgen de dulce mirada}

En sus dos pupilas bellas

Tras la pestaña rizada

De la bóveda azulada

Retratará las estrellas

Cualquiera sea el significado que pueda derivarse de tal uso del color azul, no creemos que debamos concederle mucha importancia. Y esto por la buena razón de que "Una golondrina no hace verano".

En su estudio publicado en la Revista Hispánica Moderna, dice el profesor Schulman, refiriéndose a Gutiérrez Nájera: "No sabemos exactamente quién fue el escritor que le sugirió el ejemplo del azul". 10 Tam. poco nosotros sabemos exactamente quién fue, pero pudo haber sido el español Antonio Fernández Grilo. En el número de El Siglo XIX, correspondiente al de 24 de agosto de $\mathrm{r} 874$, apareció el poema siguiente bajo la firma de Antonio F. Grilo.

Tu Traje Azul

Lo azul es lo impalpable, lo vago y misterioso Es prisma con que el cielo su túnica vistió;

Es el matiz diáfano del mar tumultuoso, La vesta [sic] que en sus vírgenes Murillo idealizó.

Es el color del lirio que el búcaro perfuma, Es la azulada ráfaga de incienso virginal, De quejumbrosa tórtola la transparente pluma, Y el fondo que se esconde del lago en el cristal.

9 Véase B. G. Carter, En torno a Gutiérrez Nájera y las letras mexicanas del siglo XIX, México, Ediciones Botas, 1960, pp. 154-158.

10 Op. cit.s p. 8. 
La banda que en el iris más fúlgida destella, La vena azul que esmalta sublime palidez, $\mathrm{Y}$ el sello que en los ojos de cándida doncella Revela de su pecho la tierna candidez.

Por eso de tu imagen hasta la sombra sigo, Por eso me enamora tu transparente tul;

Por eso te amo tanto, por eso a Dios bendigo, Que te formó tan pura como tu traje azul.

Según asentamos en el libro En torno a Gutiérrez Näjera en que se reproducet1 esta poesía, el verso "Es blanca tu conciencia y azul tu pensamiento", podría ser un recuerdo de este poema de Fernández Grilo. Reza así nuestro comentario: "No conozco otro poema de aquel tiempo, escrito en español, que anticipe de manera más acertada los procedimientos sintéticos del movimiento modernista. Es de suponer que Manuel leyó 'Tu traje azul', que le gustó y que, en lo sucesivo, el poema influyó en sus ideas sobre la estética y que lo recordó al componer su poema, 'De blanco" ".12 En una nota observamos: "Manuel se refiere a Grilo en "El arte y el materialismo' [publicado en Manuel Gutiérrez Nájera - Estudio $y$ escritos inéditos, México, Colección Stadium, No I2, I956, p. I40]: 'Al lado de las 'Flores del Mal', de Baudelaire, podemos ver aun las 'Contemplaciones' de Víctor Hugo: al lado de 'Estereoscopio social' de Alcalá Galiano, podemos mirar las poesías de Grilo y López García ...' . . . En lo tocante a los versos de Grilo, opina José Martí lo siguiente: 'Si los versos pudieran tener colores, los de Grilo serían azules y rosados'. (Véase la Revista Azul, número del I5 de septiembre de I895)".13

No es inconcebible que tanto sobre Martí como sobre Gutiérrez Nájera influyera el esquema cromático de "Tu traje azul" de Fernández Grilo. Si fuera así y si se aceptara el criterio de que a aquel escritor le correspondiera la prioridad de ser el iniciador del Modernismo, quien por primera vez usara la palabra azul en un contexto tenido por modermista, ¡entonces tendríamos que conceder este honor a un español, a don

11 p. 231-232.

12. Ibid., p. 232.

13 Ibid., nota 19. Observa Ennesto Mejia Sánchez que años después MGN dejó de estimar las poesías de Grilo: "Hasta los cartelones pintarrajeados de López García, y las estampas místicas y los bonitos cromos del señor Grilo son de nuestra época', dice en 'La coronación de Zorrilla' (Cf. Revista Nacional de Letras y Ciencias, $1^{\circ}$ de abril de 1889); con Grilo llevó más lejos su despego: 'Prefiero los cantares, los versos, los dicharachos poéticos de Vital Aza, de Estremera... a los sonetos que Grilo borda con estambre de color para uso de sus amigos...' (Cf. 'Las ruinas de Italia' en El Universal, 26 de abril de 1890)". Véase Manuel Gutiérrez Nájera, Obras. Critica literaria I. México, UNAM, 1959, pp. 62-63. 
Antonio Fernández Grilo! Por esto volvemos a observar que "Una golondrina no hace un verano".

Antes de dejar el asunto del simbolismo cromático, queremos ocuparnos del uso que hacen Martí y Gutiérrez Nájera del color blanco. El profesor Schulman opina que en los escritos de Martí "las primeras apariciones de blanco-1875- señalan la pauta para los usos posteriores" y cita los textos siguientes:

Luisa Pérez es algo como nube de nácar y azul en tarde serena y bonancible.

Virgen sin huella del cansancio humano;

Virgen sin mancha de impudor ni hastio, Que abierta llevas en la casta mano

La blanca flor que ansiaba el amor mío.

A alguna niña, vimos, criatura que al decir de Mercado, se está desprendiendo de la tierra y a quien algún hombre joven y generoso se hubiera regocijado de ver. Es ella blanca y rubia, como allá en las Iocuras escondidas se imaginan el candor y la pureza. Y vestía, sin embargo, de negro aquella purísima alma blanca.

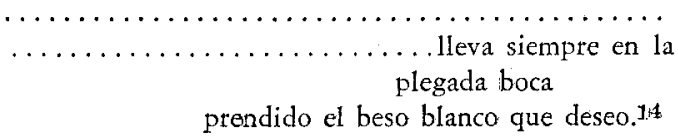

Según anota el profesor Schulman, es el blanco "el color personal de Nájera"15 y "no importa el tema de la poesía, lo blanco siempre simboliza lo perfecto, lo inmaculado e ideal" 16 En otro lugar observa: " De blanco' (I888) es la poesía por excelencia de la técnica cromática. En ella Nájera furde procedimientos simbolistas y parnasianos en un afán por expresar los aspectos plásticos del color, y al mismo tiempo deshacerse de las restricciones del mundo material y recrearse en la contemplación de un color en abstracto". 17

En el libro aparecido en 1956, publicamos ${ }^{18}$ una poesía inédita de

1H Véase Simbolo y color en la obra de José Marti, pp. 480-481. Se anota en la pág. 481 que los versos de la última cita son tomados del poema "La vi ayer, la vi hoy" (1875).

15 "El color en la poesía de Manuel Gutiérrez Nájera", op. cit., p. 10.

16 Ibid., p. 13.

17 Ibid., p. 11.

18 Manuel Gutiérrez Nájera-Estudio y escritos inéditos, pp. 46-57; 81-83. 
Gutiérrez Nájeta titulada "iVen a mi gruta!", que descubrimos en $E l$ Correo Germánico ( $\mathrm{N}^{\circ}$ 19, I2 de septiembre de I876). Consignamos esta opinión sobre dicho poema: " . . creemos no equivocarnos al ver en " $i$ Ven a mi gruta!' el bosquejo de uno de sus más conocidos poemas, 'De blanco', publicado unos doce años más tarde. Notamos en 'iVen a mi gruta!' las siguientes palabras que sugieren lo blanco: blancas perlas, blanca copa, blanca paloma (aparece ésta en tres estrofas), cándida espuma, el vapor, blancas ( $y$ purpurreas) rosas, azucena, luminar del dia, manantial cristalino, pálida, lirio". "19 También aparece el color blanco varias veces en el poema "Serenata" (1875): blanca luna, rayo, paloma, estrella de la mañand, astro, blanco lucero. Muchas palabras que sugieren lo blanco también se hallan en otros tres poemas publicados en los años 1876 y 1877 .

"Luz y sombra" ( 1876$)$ : blanca aurora, casta luna, blanca estrella, azucena, cándido arroyuelo, blanca conciencid, cándidos amores, blanca luz.

"Mi casa blanca" (I877): fúlgidio sol, blanca casita, blancos rosales, pálido albor, pálida luz, pálidos lirios, clara laguna, pálido rayo, pálida faz, blanca azucena, livio, blanca paloma, pálida alrora.

Los siguientes versos of recen tantos rasgos de similitud con los de "De blanco", que casi dan la impresión de haber sido entresacados de este poema.

\footnotetext{
Las gotas cuajadas de fresco rocío, relucen cual perlas del sol a la luz, y en medio a las nieblas que se alzan del río del blanco santuario se mira la cruz.
}

"Albores primaverales" (1877): albores, auroras, paloma, blanquecinos muros, la luz, casita blanca, cielo diáfano, bumo blanco, pálida luna.

Hay que notar también que en el poema "De blanco" se encierran ciertos elementos, temas, imágenes, palabras, ritmos y conciertos mnemotécnicos, que se encuentran en el poema "Amor y muerte", de autor desconocido, que se publicó por primera vez, que sepamos, en La Ilustración Mexicana en I85I. Manuel publicó dos versiones suyas de este poema, la primera en $\mathrm{El}$ Curreo Germánico ${ }^{20}$ (1876) y la segunda en La Voz de Españd ${ }^{21}$ (1879). En este contexto nos permitimos llamar la atención sobre esta poesía con el motivo de señalar la influencia de las letras mexicanas en la obra de Gutiérrez Nájera.

19 Ibíd, p. 51. Véase también las páginas 52-53.

20 Véase Manuel Gutiérrez Nájera-Estudio y escritos inéditos, pp. 46-55.

121 Véase En torno a Gutiérrez Nájera, pp. 23-36. 
En cuanto al simbolismo de lo blanco, hemos visto que ya se encuentra como elemento esencial en sus primeros escritos. De paso, es de observarse que el profesor Schulman no sostiene la prioridad de Martí sobre Gutiérrez Nájera en el uso de lo blanco. Sin embargo, nos parece digno de advertirse que siendo todavía un adolescente entre los diez y seis y diez y ocho años, Manuel ya tuvo conciencia del uso estilístico que podía hacerse de los colores. En "De blanco" ( I888), su poema de máxima saturación cromática, se hallan tal vez más recuerdos de las composiciones juveniles ("Serenata", I875; "iVen a mi gruta!", I876; "Luz y sombra", I876; "Mi casa blanca", I877; "Albores primaverales", r877) que rasgos y elementos de otra índole y procedencia.

\section{III}

En el libro Manuel Gutiérrez Nájera - Estudio y escritos inéditos, pp. I3-23, referimos de qué modo la mera cásualidad nos llevó a descubrir en I954 varios escritos de Gutiérrez Nájera que se publicaron en El Correo Germánico. Apareció el primer número de este periódico el $\mathrm{I}^{9}$ de agosto de r876, y el último el I4 de octubre del mismo año; en total, 33 números. En otro libro presentamos datos biográficos sobre el redactọr de El Correo Germánico, Otto E. Freiherr von Brackel-Welda. quien colaboró en la revista El Propagador Industrial bajo la dirección de Manuel Gutiérrez, padre de El Duque Job. En esta revista, que se pu. blicó desde el 16 de abril de 1875 hasta el $I^{2}$ de julio de I876, aparecieron algunas traducciones del francés de escritos científicos ${ }^{23}$ hechas por Gutiérrez Nájera. Así sabemos que al tener diez y seis años Manuel sabía leer el idioma.

Desde luego, el escrito de más significación de Manuel publicado en El Correo Germánico, periódico trisemanal, fue el largo ensayo (cerca de 7,000 palabras) titulado "El arte y el materialismo".24 Débese este ensayo sobre el arte y el materialismo a una polémica que inició Francisco Sosa en El Federalista, que sostuvo Gutiétrez Nájera en La Iberiat, tuvo eco en El Monitor Republicano y, trasladada a El Corréo Germánico, obscura hoja con mucha ambición y vida breve, terminó en la publicación de la

29 En torno a Gutiérrez Nájera, pp. 15-22.

23 Ibid., pp. 18-19.

2it Reproducido en Manuel Gutiérrez Nájera-Estudio y escritos inéditos, pp. 113-44, y en Manuel Gutiérrez Nájera.Obras, Crítica Literaria I. Universidad Nacional Autónoma de México, 1959, pp. 49-64. 
obra de más alcances y enfoques de orden estético que hasta aquel entonces se había dado a la luz en México: "El arte y el materialismo". ${ }^{25}$ Las citas siguientes, sacadas de este escrito, servirán para dar una idea de su manera de concebir el arte, cuando Manuel tiene sólo diez y siete años.

\section{La libertad en el arte:}

Lo que nosotros queremos, lo que siempre hemos defendido, es que no se sujete al poeta a cantar solamente ciertos y determinados asuntos, porque esa sujeción, tiránica y absurda, ahoga su genio... (p. 119). ${ }^{26}$

El positivismo y el arte:

Lo que nosotros combatimos y combatiremos siempre, es esa materialización del arte, ese asqueroso y repugnante positivismo que en mal hora pretende introducir en la poesía;... (p. 121).

El abjeto del ditte:

... Intentaremos demostrar al critico del Monitor: $1^{9}$ Que el arte tiene por objeto la consecución de lo bello; $2^{\circ}$ que lo bello no puede encontrarse en la materia, sino con relación al espíritu; y $3^{\circ}$ que el amot es una inagotable fuente de belleza... (p. 123).

\section{Lo bello y lo utitl:}

...Los filósofos que con más particularidad se han ocupado de la Estética, dicen que así como la industria tiene por principio lo útil, el arte tiene por principio lo bello. Ahora bien: ¿a qué llamamos útil?, ¿a qué llamamos bello? "Lo bello - dice admirablemente Platón- es el resplandor del verdadero"; y San Agustín añade: "el brillo de lo bueno"; Rousseau decía que lo único verdaderamente bello, fuera del Ser Supremo que existe por sí mismo, es aquello que no existe. El escéptico Goethe hacía consistir la belleza en la expresión; Hirt on aquello que llamaba lo caracteristico.

Para nosotros, lo bello es la representación de lo infinito en lo finito; la manifestación de lo extensivo en lo intensivo; el reflejo de lo absoluto; la

25 Para datos sobre esta polémica, incluso su origen y desarrollo y la identidad de P. T., el crítico de El Monitor, cuyos comentatios impulsaron a Manuel a escribir "El arte y el materialismo", véase Manuel Gutiérrez Nájera - Estudio y escritos inéditos (1956), pp. 29-45.

26 Los números en paréntesis se refieren a Manuel Gutiérrez Nájera-Estudio $y$ escritos inéditos.

Para poner de relieve el concepto que tiene de la libertad en el arte, se sirve Manuel de la imagen del "ave que... alza su atrevido vuelo..." y "esa misma ave que presa por la red astuta del cazador..." y "encerrada en... su jaula... sólo exhala tristísimo lamento..." (p. 130). Como lo demuestra el profesor Schulman, lo simbólico del ave libre que vuela y del ave presa o caida, desempeña un papel importante en el dualismo filosófico de Martí. Véase Símbolo $y$ color en la obra de José Martí, pp. 124-149. 
revelación de Dios. Para nosotros el sentimiento de lo bello es innato en el hombre;... (p. 124).

\section{La naturaleza de lo bello:}

¿Qué es lo bello?

Si no lo sentís en vuestro espíritu, no pretendáis que nosotros os demos su definición; lo bello no se define, se siente...

La belleza, tal como nosotros podemos comprenderla, no es una idea, sino la imagen de una idea,... (p. 125).

\section{La belleza y el idealismo:}

Pero si, como ya lo hemos dicho, la belleza reside en el orden espiritual y no en el de la materia, claro es que debemos encontrarla en el idealismo, que mira al cielo, y no en el materialismo, que fija sus ojos en la tierra. (pp. 129-130).

\section{El arte no es imitación:}

Se ha creído por alguno, que el abjeto del arte es la imitación de la naturaleza y esta creencia es, según nuestro entender, evidentemente errónea.

Si el único principio del arte fuera la imitación, un término supremo consistiría en la completa ilusión de los sentidos, y si tal fuese necesario, sería convenir en que el artista más sublime sería el espejo que con más fidelidad retratase los objetos. ¡Error monstruoso! (pp. 132-133).

Figuraos que dos artistas, a imitación de Breughel, pintan dos cuadros representando a Adán y a Eva en el paraíso; ¡soberbio asunto para ensayar la paleta!... (p. 134).

Los dos pintores hacen sus cuadros y los entregan al fallo del público.

El primer paraíso con que nos encontramos es una fotografía de la verdad material. Adán y Eva están realmente en cueros,... Las plantas y los árboles podrían ser clasificados por un botánico,...

Pero después de haber admirado todo esto con los ojos de la cara, echáis de ver que no se ha asomado a ellos vuestra alma... (pp. 134-135).

El segundo paraíso deja en cambio mucho que desear como fiel imitación. No se comprende bien qué átboles son aquéllos; hay acaso algún león con peluca y algún elefante que tiene grandes narices en vez de trompa; hay faltas de corrección en el dibujo y grande escasez de detalles: empero, la composición es grandiosa; los pájaros cortan el aire, los brutos corren por la pradera mostrando su variedad infinita y como negándose a la servil imitación; el aire y la luz lo bañan todo en olas de color y de alegría, modificando y transformando los objetos... (pp. 135-136).

\section{El arte delinea la lucha de la materia y del espiritu}

Lo que de la pintura hemos dicho en nuestro último artículo, se ex. tiende a todos los demás ramos del arte que no son, en rigor de verdad, sino las múltiples y varias manifestaciones de un solo principio. 
Volved la vista a la poesía, a la música, a la arquitectura, en todas veréis perfectamente delineadas las tendencias de que antes hablamos: Ia materia y el espíritu en su perpetua e incesante lucha;... (p. 137).

El crítico mexicano Porfirio Martínez Peñaloza, influido por el interés que manifestaba Manuel por Alemania en 1876 (dicho interés debido acaso a la asociación del joven con el Barón de Brackel-Welda), ve en estos escritos "la confirmación de cierta nota germánica en su formación literaria $y$, por consiguiente, en su poesía".27 El mismo crítico compara las ideas de Gutiérrez Nájera sobre la estética, tal como el poeta las presenta en "El arte y el materialismo", con las de Hegel, y coteja varios textos de los dos escritores con motivo de señalar los rasgos de identidad entre ellos. ${ }^{28}$ De que existen parelelos muy sugestivos entre las ideas proferidas por Manuel sobre la estética en "El arte y el materialismo" y las ideas de Hegel, de esto no cabe duda. Pero también es verdad que nada es más difícil que el averiguar con certeza de dónde saca un genio sus ideas y el porqué de la forma particular en que las expresa. A este respecto conviene notar que Manuel pudo haber formulado algunas de sus nociones sobre la estética bajo la influencia del "Prefacio" de Cromwell (1827) de Víctor Hugo, del "Prefacio" de Mlle. Maupin (I835) de Teófilo Gautier, así como de algunos de los prefacios de Lamartine. Estos autores, al igual que otros, asientan juicios sobre el fin del arte, la índole de lo bello, el arte por el arte, la libertad en el arte, etc. Tales conceptos circularon extensamente en el siglo XIX, en México como en Europa. Así, Manuel pudo haberlos encontrado no sólo en las obras de Hegel, de Hugo, de Gautier, de Lamartine, sino también en los escritos de Francisco Zarco. Nos referimos al "Discurso sobre el objeto de la literatura", pronunciado el dia I de junio de I85I por Zarco al tomar posesión de la presidencia del Liceo Hidalgo. El Discurso se publicó en La Ilustración Mexicana (T. I, I85x, pp. I6I-I68) y volvió a aparecer en El Eco de Ambos Mundos (T. I, 1873, Pp. I5I-I57). Sabemos que Manuel conocia este tomo de La Ilustración Meixicana porque en él se publicaron (en forma anónima) las dos poesías "Amor e infortunio" y "A una flor", de las cuales aparecieron en r876 versiones suscritas por "M. Gutiérrez" en El Correo Germánico. El otro escrito que aludimos se titula "La música" y se publicó en La Semana de las Señoritas (T. I, I852, nueva época, pp. 102-107). Sea que la estética de Gu-

27 "Escritos inéditos de Gutiérrez Nájera", en México en la Cultura, suple. mento literario editado por Novedades, 12 de mayo de 1957.

28 Véase ibíd., número 27 de mayo de 1957. 
tiérrez Nájera cae dentro de "la órbita del hegelianismo",20 se remonta a las fuentes francesas mencionadas o refleja el pensamiento de Zarco, no cabe duda de que "revela una temprana madurez intelectual", 30 según observa Francisco González Guerrero.

En 1956 dijimos sobre "El Arte y el materialismo":

Manuel Gutiérrez Nájera tiene derecho al título de precursor: teórico del modernismo en el dominio de lo estético por haber tenido y defendido los siguientes puntos de vista: $1^{9}$ el arte no es imitación sino creación; $2^{\circ}$ el artista debe ser libre de escoger su tema y desenvolverlo a su gusto; $3^{9}$ el objeto del arte es la belleza; $4^{\circ}$ la belleza, no siendo una idea sino la imagen de una idea, existe y se logra artísticamente en niveles simbólicos, distintos, superiores; $5^{\circ}$ el arte representa el triunfo de lo ideal sobre lo material, es decir, el triunfo de Ariel sobre Calibán; $6^{\circ}$ la propaganda no tiene nada que ver con el arte; $7^{\circ}$ lo utilitario de índole material, es el enemigo implacable del arte; $9^{\circ}$ lo bello es útil por ser bello. Además, al mismo tiempo que desprecia a Europa por ser decadente, y recomienda que el Nuevo Mundo deje de llevar su carcomido yugo cultural, Manuel da muestra. del más auténtico cosmopolitismo intelectual y de compenetraciones. literarias y artísticas de procedencias tan distintas en punto a geografía como a tendencias ideológicas y estéticas. (pp. 78-79).

Porfirio Martínez Peñaloza, 31 al comentar dicho ensayo, dice: "Como se puede ver, la formulación de esta estética fue anterior a casi toda la abra del poeta y la sostuvo durante toda la vida... En consecuencia su poesía debe considerarse como la plasmación de estos ideales estéticos":32 En la "Nota preliminar" a su estudio, Simbolo y color en la obra de José Martí, el profesor Schulman parece aceptar la conclusión de don Federico de Onís de que "el primero y más grande de los creadores" del Modernismo fue José Martí. "Contemporánea de él es la primera generación de poetas modernistas, que suelen llamarse precursores, pero que en rigor son los creadores de la nueva litetatura en el verso y la prosa..."33 Según afirma Federico de Onís, Martí "... en su prosa lírica -ensayos, discursos, cartas-y en sus versos libres o sencillos, inicia,

29 Ibid.

30 Véase Estudio preliminar a Manuel Gutiérrez Nájera: Cuentos y otras narraciones, prólogo, edición y notas de E. K. Mapes. México, Fondo de Cultura Económica, 1958, p. xxii.

31 Véase Manuel Gutiérrez Nájera-Estudio y escritos inéditos, pp. 78-79; y también Francisco González Guerrero, op. cit., pp. xxi-xxii, quien reproduce nuestra opinión y también la de Martínez Peñaloza.

2:2 Véase Novedades, 27 de mayo de 1957; y también Francisco González Gue. rrero, op. cit., p. xxii.

93 Opiniones citadas por Schulman, op. cit., pp. 12-13. 
con uno de los estilos más personales de la lengua castellana, los temas y actitudes que van a perdurar y desarrollarse de manera varia y creciente hasta hoy..."34 En el párrafo que sigue esta cita (p. I3), el profesor Schulman afirma que:

"No sólo se demostró que era [la prosa de Martí] abundante en imágenes, variada en sus formas rítmicas, plástica y sensual en su calidad, sino que, entre 1877 y 1882 -antes de producirse ninguna poesía modernista de gran valor- había desarrollado los rasgos más importantes de lo que más tarde iba a representar la doctrina estética del Modernismo". ${ }^{35}$ Luego, anota el autor con respecto al "cuerpo de ideas estéticas asombrosamente abundante y detallado" en la obra de Martí que "un estudio reciente de Alfredo A. Roggiano prueba sin lugar a duda que, aunque expresado de manera asistemática en prólogos, ensayos y versos, el cuerpo de doctrina estética de Martí constituye uno de los más admirables en lengua española, comparable con los mejores de otras culturas y lenguas". ${ }^{36}$ De aquí que el profesor Schulman concluya en estos términos: "Estas formulaciones teóricas demuestran claramente la prioridad en el tiempo que corresponde a Martí en cuanto a la introducción de las ideas que más tarde fueron incorporadas como elementos primordiales a la estética modernista" (p. I4).

Es evidente que el autor de este juicio se olvidó de tomar en cuenta la existencia del ensayo de Gutiérrez Nájera sobre " $\mathrm{El}$ arte y el materialismo" (I876) cuando escribió esta última oración. En la reseña que dedicó a Manuel Gutiérrez Nájera - Estudio y escritos inéditos, el profesor Schulman dice:

....El Profesor Carter opina que "...tal vez debe considerarse como el primer manifiesto del modernismo" (p. 76). No podemos compartir semejante juicio. El hecho de que se aluda a la necesidad de la libertad en el proceso creador, la belleza como fin y objeto del arte, el arte como el triunfo de lo ideal sobre lo material, etc., no indica una declaración estética de índole modernista. Parecidos principios pertenecen a la estética idealista universal y pueden encontrarse en muchos manifiestos literarios, incluso el prefacio que a su drama Cromwell puso Víctor Hugo.,37

Echase de ver que en el concepto del profesor Schulman poco vale "El arte y el materialismo" como ensayo sobre la estética y lo tiene en

34 Ibid., p. 12.

as Ibid., p. 13.

36 Ibid., pp. 13-14. Véase Alfredo A. Roggiano, "Poética y estilo de José Marti", Humanitas, Revista de la Facultad de Filosofía y Letras (Tucumán, Argentina), I (1953), 351-378.

37 Revista Hispánica Moderna, XXIII, núm. 2, abril de 1957, pp. 163-164. 
menos. ${ }^{38}$ Otros críticos no comparten el punto de vista suyo. En lo referente a nuestra creencia de que dicho ensayo de Gutiérrez Nájera "tal vez debe considerarse como el primer manifiesto del modernismo", dice el profesor Allen W. Phillips: "It may be an exaggeration to consider it as the first munifiesto of modemismo (p. 76), but it does express some key aspects of la nueva sensibilidad and constitutes a significant document for the history of aesthetic ideas in Spanish America". ${ }^{39}$ Opina José Manuel Topete: "Tiene razón Carter al afirmar que es 'El arte y el materialismo' uno de los primeros manifiestos del Modernismo". 40

Por más que el profesor Schulman atribuya poca importancia a "El arte y el materialismo", no se concibe su intento de querer tratar de establecer la prioridad de Martí como teórico del Modernismo sin tomar en cuenta dicho ensayo de Gutiérrez Nájera. En todo caso sólo podría tratarse de algún descuido.

En la reseña de nuestro libro (véase nota 37) parece afirmat el profesor Schulman que "El arte y el materialismo" no es "una declaración estética de indole modernista". Sería interesante saber cómo el profesor Schulman define el Modernismo y cuáles son las pruebas que podría aducir en apoyo de su punto de vista. De todos modos, antes de que se pueda admitir la prioridad de Martí como teórico del Modernismo hay que señalar algún escrito suyo de semejante significado que se haya dado a la luz pública con anterioridad al de Gutiérrez Nájera en 1876 o demostrar con pruebas fehacientes que las ideas que asienta Manuel sobre la estética no tienen nada que ver con el conjunto de las creencias y conceptos literarios que se suelen asociar con los escritores del Modernismo.

Notemos, por último, que si de Martí tenemos ya publicadas las obras completas (o casi todas), de Gutiérrez Nájera, por el contrario, no se ha publicado sino una pequeña parte de sus escritos. De los manuscritos recopilados por el profesor Mapes y que han de ser editados por la Universidad Nacional Autónoma de México, sólo un volumen, el titulado Crítica literaria I (1959), ha sido publicado hasta ahora.

De conformidad con el deseo del profesor Mapes, de que se encargara el que esto escribe de la tarea de ayudar a llevar a cabo su labor interrumpida, la señora Mapes ha puesto el archivo Gutiérrez Nájera a

38 No se incluye el título del libro en que se publicó por primera vez "El arte y el materialismo", es decir, Maneul Gutiérrez Nájera-Estudio y escritos iné. ditos, en la bibliografía del libro del profesor Schulman, Color y simbolo en la obra de José Martí.

39 Véase Hispanic Review, XXV, núm. 4, octubre de 1957, pp. 308-310. 302-303.

40 Revista Interamericana de Bibliografía, vol. VII, núm. 3, 1957 , pp. 
nuestra disposición. Nada fácil será atar los hilos sueltos, ordenar tantos materiales, y dar impulso al conjunto de actividades, investigaciones y estudios graduados que deben relacionarse con un proyecto de esta índole para que salga con éxito. Sin embargo, hasta que no se hayan publicado las obras completas de Gutiérrez Nájera, es evidente que no será posible hacer el balance de sus realizaciones como escritor y apreciar con plenitud los alcances de su genio. Ni será posible averiguar con la precisión debida lo que pueda representar el significado de su mundo de creencias, de pensamientos, de sueños, de imágenes, etcétera. Mientras tanto, según la evidencia que se ha aducido, parece prematuro concederle a Martí, antes que a Gutiérrez Nájera, el título de primer iniciador del Modernismo.

Soutbern Illinois University

Boy G. Carter 